\title{
PRODUCTION OF SUNFLOWER (Helianthus annuus L.) AS A FLOWERING POT PLANT USING DIFFERENT POTTING MEDIA AND GROWTH RETARDANT TREATMENTS
}

\author{
(Received:28.10.2009)
}

\author{
By \\ H. A. Mansour, E. I. El-Maadawy and I. Z. Othman \\ Ornamental Horticulture Department, Faculty of Agriculture, Cairo University, Giza, Egypt.
}

\begin{abstract}
This study was carried out in the experimental nursery of the Ornamental Horticulture Department, Faculty of Agriculture, Cairo University, during the two successive years of 2007 and 2008. The aim of this study was to investigate the possibility of growing sunflower (Helianthus annuus L.) as a pot plant using different potting media and growth retardant treatments. The plants were grown in $25-\mathrm{cm}$ pots filled with clay, clay+sand $(1: 1, \mathrm{v} / \mathrm{v})$, clay+peat $(1: 1, \mathrm{v} / \mathrm{v})$ or sand+peat $(1: 1, \mathrm{v} / \mathrm{v})$, and were treated twice with paclobutrazol as a soil drench at $1.5,3.0,4.5$ or $6.0 \mathrm{mg}$ a.i./pot, or with Pix (mepiquat chloride) as a foliar spray at $500,1000,1500$ or $2000 \mathrm{ppm}$, plus the control. The recorded results showed that using clay+peat $(1: 1, \mathrm{v} / \mathrm{v})$ gave the best results for all the studied vegetative growth and flowering characteristics. In most cases, the different growth retardant treatments decreased plant height. The shortest plants were achieved with using paclobutrazol at $6 \mathrm{mg}$ a.i./pot (in the first season) or Pix at $2000 \mathrm{ppm}$ (in the second one). Growth retardant treatments (poclobutrazol or Pix) also decreased flower diameter, but increased the fresh and dry weights of flower-heads.
\end{abstract}

Key words: Helianthus annuus, mepiquat chloride, paclobutrazol ,sunflower.

\section{INTRODUCTION}

Flowering pot plants represent one of the most interesting and promising typologies of ornamental production, and frequently new species or products are selected for marketing. In view of the positive trend shown in the last years by the increase in production of flowering pot plants, the use of sunflower (Helianthus annuus L.) as a flowering pot plant, though quite unusual for this species, could represent a powerful innovation. On the other hand, as for any new product, there is a lack of information about the cultivation technique and the appropriate practices for getting the best results in producing high quality potted sunflower (Vernieri et al,. 2003). The cultivation of ornamental sunflower has increased during the past few years in Egypt, as cut flowers and pot plants. Several management practices are used for the production of pot ornamental plants, and among them the use of growth retardants (Bonacin et al., 2006).

Many growth retardants, such as triazole salts, are synthetic chemicals previously introduced in the horticultural production scale as steroidal herbicides. Practically, these retardants are more effective than others, i.e., lower concentration or active ingredient levels are adequate to produce similar effects to higher concentrations of other retardants (Law and Hamilton, 1989).

This study was conducted with the aim of investigating the effect of different types of potting media, as well as growth retardant [PP333 (paclobutrazol) and Pix (mepiquat chloride)] treatments on the vegetative growth and flowering of sunflower (Helianthus annuus) plants. The information provided by this study may help in the successful production of $H$. annuus as flowering pot plants.

\section{MATERIALS AND METHODS}

This study was carried out at the experimental nursery of the Ornamental Horticulture Department, Faculty of Agriculture, Cairo University, during the two successive years of 2007 and 2008. The aim of this study was to investigate the possibility of growing sunflower (Helianthus annuиs) as a pot plant using different potting media and growth retardant treatments.

\subsection{Experimental procedures}

On the $5^{\text {th }}$ of March, 2007 and 2008 (in the first and second seasons, respectively) F1 seeds of sunflower (Helianthus annuus) were obtained from the nurseries of Floramix Co., El-Maryoutia, Giza Governorate. The seeds 
were sown individually in plastic pots (25$\mathrm{cm}$ in diameter) filled with clay, clay + sand $(1: 1, \mathrm{v} / \mathrm{v})$, clay + peat moss $(1: 1, \mathrm{v} / \mathrm{v})$, or sand + peat moss $(1: 1, \mathrm{v} / \mathrm{v})$. The physical and chemical characteristics of sand, clay and peat moss are shown in Table (1). The pots were placed in a sunny area, and thick polyethylene sheets were spread underneath the pots to prevent the roots from growing into the soil.

Table (1): Physical and chemical characteristics of the sand, clay and peat moss used for growing Helianthus annuus plants during the 2007 and 2008 seasons.

\begin{tabular}{|c|c|c|c|}
\hline Soil characteristics & Sand & Clay & $\begin{array}{l}\text { Peat } \\
\text { moss }\end{array}$ \\
\hline \multicolumn{4}{|c|}{ Physical characteristics } \\
\hline CEC (meq/100g) & 5.30 & 39.40 & $\begin{array}{l}100- \\
150\end{array}$ \\
\hline Field capacity (\% v) & 16.00 & 67.30 & 50 \\
\hline \multicolumn{4}{|c|}{ Chemical characteristics } \\
\hline Organic matter (\%) & 1.10 & 2.05 & 58 \\
\hline pH & 7.90 & 7.12 & $3-4$ \\
\hline$E C(d S / m)$ & 2.25 & 1.67 & 2.3 \\
\hline $\mathbf{N}(\mathbf{p p m})$ & 13.13 & 93.35 & 13000 \\
\hline $\mathbf{P}(\mathbf{p p m})$ & 7.40 & 20.25 & 6000 \\
\hline K (ppm) & 48.65 & 71.85 & 7900 \\
\hline Mg (ppm) & 24.60 & 36.80 & - \\
\hline $\mathrm{Fe}(\mathrm{ppm})$ & 2.90 & 2.10 & 620 \\
\hline Mn (ppm) & 2.80 & 3.10 & 153 \\
\hline Zn (ppm) & 0.90 & 1.56 & 38 \\
\hline $\mathrm{Cu}(\mathbf{p p m})$ & 0.75 & 1.56 & - \\
\hline
\end{tabular}

In both seasons, plants grown in each of the tested growing media were treated with PPP-333 (paclobutrazol) as a soil drench at the rates of $1.5,3.0,4.5$ and $6 \mathrm{mg}$ a.i./pot, or with Pix (mepiquat chloride) applied as a foliar spray at concentrations of 500, 1000, 1500 and $2000 \mathrm{ppm}$. The growth retardant treatments were applied on the $20^{\text {th }}$ of March and the $5^{\text {th }}$ of April in the first and second seasons, respectively, and the treatments were repeated two weeks after the first application. Control plants were also included within each of the four growing media.

Common cultural practices were followed, including regular watering, hand picking of weeds, as well as fertilization using the soluble chemical fertilizer Kristalon (NPK, 19-19-19), which was applied twice (on $18^{\text {th }}$ March and $25^{\text {th }}$ April, 2007 and 2008 in the first and second seasons, respectively), at the rate of $0.5 \mathrm{~g} /$ pot.

The layout of the experiment was a randomized complete blocks design, with 36 treatments $[9$ growth retardant treatments (including the control) X 4 growing media], and 4 blocks (replicates), each consisting of 72 plants ( 2 plants/treatment).

On the $5^{\text {th }}$ of June 2007 and 2008 (in the first and the second season, respectively), the experiment was terminated, and the data were recorded on the different vegetative growth characteristics [plant height, as well as plant (leaves+stems+roots) fresh and dry weights]. Also, the data were recorded on the flowering characteristics, including flowerhead diameter, and the fresh and dry weights of the flower-head.

The data recorded on the vegetative growth and flowering were statistically analyzed. An analysis of variance (ANOVA) was carried out, and the means of the recorded data were compared using the "Least Significant Difference (L.S.D.)" test at the $5 \%$ level, as described by Steel and Torrie (1980).

\subsection{Vegetative growth \\ 3. RESULTS AND DISCUSSION \\ 3.1.1. Plant height}

The data presented in Table (2) show that the height of Helianthus annuus plants was significantly affected by the medium in which the plants were grown. In both seasons, the shortest plants were those grown in clay+sand. On the other hand, plants grown in clay+peat or sand+peat were significantly taller in the first season, compared to the plants grown in clay or clay+sand. The enhancement of plant growth (in terms of plant height) as a result of using the clay+peat medium was also clear in the second season, with the tallest plants $(44.40 \mathrm{~cm})$ being those grown in this medium (clay+peat). However, unlike the first season the plants grown in sand+peat were significantly shorter in the second season than those grown in clay.

The application of growth retardants (paclobutrazol or Pix) also had a significant effect on the height of Helianthus annuus plants. In the first season, the tallest plants were those receiving no paclobutrazol or Pix treatments (control). Application of any rate of paclobutrazol or Pix caused a significant reduction in plant height. Paclobutrazol was generally more effective than Pix for height control of sunflower plants in the 
first season. It is also clear from the data in Table (2) that, in the first season, raising the application rate of any of these two chemicals caused a steady reduction in plant height. The shortest plants obtained in the first season were those treated with the highest paclobutrazol rate $(6 \mathrm{mg}$ a.i./pot). In the second season, the different growth retardants caused significant decreases in plant height, compared to the control, except the application of paclobutrazol at $6 \mathrm{mg}$ a.i./pot, which gave insignificantly taller plants than the control. The most effective growth retardant treatment in the second season (i.e., giving the shortest plants) was spraying the plants with the highest Pix concentration (2000 ppm). Several researchers reported that growth retardants can be used to decrease the height of different ornamental plant species, including sunflower [Dasoju et al. (1998), Whipker and McCall (2000), Gimelli et al. (2003), Incrocci et al. (2003), Vernieri et al. (2003), Whipker et al. (2004), and Wanderley et al. (2007)], zinnia [Cox and Keever (1988), Taychasinpitak and Manochai (2003), and Pinto et al. (2005)], geranium (Cox and Keever, 1988),

Table (2): Effect of growing media and growth regulator treatments on plant height of sunflower (Helianthus annuus) during 2007 and 2008 seasons.

\begin{tabular}{|c|c|c|c|c|c|}
\hline \multirow{3}{*}{$\begin{array}{c}\text { *Growth regulator } \\
\text { treatments }(\mathbf{G R})\end{array}$} & \multicolumn{5}{|c|}{ Plant height (cm) } \\
\hline & \multicolumn{4}{|c|}{ Growing media (GM) } & \multirow{2}{*}{ Mean (GR) } \\
\hline & Clay & Clay+ sand & Clay+ peat & Sand+ peat & \\
\hline & \multicolumn{5}{|c|}{ First Season (2007) } \\
\hline Control & 48.13 & 42.13 & 51.25 & 52.75 & 48.56 \\
\hline $\begin{array}{l}\text { Pac }(1.5 \mathrm{mg} \\
\text { a.i./pot) }\end{array}$ & 37.75 & 33.63 & 49.38 & 44.88 & 41.41 \\
\hline Pac (3 mg a.i./pot) & 32.00 & 31.75 & 45.63 & 41.25 & 37.66 \\
\hline $\begin{array}{l}\text { Pac }(4.5 \mathrm{mg} \\
\text { a.i./pot) }\end{array}$ & 25.75 & 30.38 & 44.13 & 41.63 & 35.47 \\
\hline Pac (6 mg a.i./pot) & 28.50 & 26.75 & 33.13 & 41.63 & 32.50 \\
\hline Pix (500 ppm) & 41.00 & 43.38 & 47.38 & 46.25 & 44.50 \\
\hline Pix (1000 ppm) & 43.75 & 31.25 & 41.00 & 49.75 & 41.44 \\
\hline Pix (1500 ppm) & 41.88 & 44.00 & 42.38 & 41.75 & 42.50 \\
\hline Pix (2000 ppm) & 35.25 & 34.63 & 43.13 & 43.75 & 39.19 \\
\hline Mean (GM) & 37.11 & 35.32 & 44.15 & 44.85 & --- \\
\hline \multicolumn{6}{|l|}{ LSD (0.05) } \\
\hline GR & \multicolumn{5}{|c|}{3.39} \\
\hline GM & \multicolumn{5}{|c|}{2.26} \\
\hline \multirow[t]{2}{*}{ GR X GM } & \multicolumn{5}{|c|}{6.78} \\
\hline & \multicolumn{5}{|c|}{ Second Season (2008) } \\
\hline Control & 47.50 & 39.88 & 49.06 & 42.38 & 44.70 \\
\hline $\begin{array}{l}\text { Pac }(1.5 \mathrm{mg} \\
\text { a.i./pot) }\end{array}$ & 43.50 & 39.00 & 39.63 & 41.50 & 40.91 \\
\hline Pac (3 mg a.i./pot) & 43.13 & 34.63 & 38.50 & 41.13 & 39.34 \\
\hline $\begin{array}{l}\text { Pac }(4.5 \mathrm{mg} \\
\text { a.i./pot) }\end{array}$ & 41.63 & 34.00 & 45.69 & 36.63 & 39.48 \\
\hline Pac (6 mg a.i./pot) & 44.13 & 40.06 & 51.75 & 45.00 & 45.23 \\
\hline Pix (500 ppm) & 40.75 & 39.88 & 44.75 & 36.04 & 40.35 \\
\hline Pix (1000 ppm) & 44.00 & 33.88 & 46.50 & 41.63 & 41.50 \\
\hline Pix (1500 ppm) & 41.13 & 41.50 & 43.75 & 36.63 & 40.75 \\
\hline Pix (2000 ppm) & 42.19 & 36.88 & 40.00 & 34.69 & 38.44 \\
\hline Mean (GM) & 43.10 & 37.74 & 44.40 & 39.51 & --- \\
\hline \multicolumn{6}{|l|}{ LSD (0.05) } \\
\hline GR & \multicolumn{5}{|c|}{1.99} \\
\hline GM & \multicolumn{5}{|c|}{1.32} \\
\hline GR X GM & \multicolumn{5}{|c|}{3.97} \\
\hline
\end{tabular}


chrysanthemum (Bhat and Tayama, 1989), Tagetes erecta (Girwani et al., 1990), and Fuchsia magellanica (Gad et al., 1997).

Regarding the interaction between the effects of growing media and growth retardant treatments on plant height, the data in Table (2) show that, in the first season, the tallest plants $(52.75 \mathrm{~cm})$ were those that received no growth retardants (control), and were grown in clay+peat or sand+peat, resulting from these treatments). In the second season, the tallest plants were those grown in clay+peat and supplied with no growth retardant or plants grown in the same medium (clay+peat) and treated with paclobutrazol at $6 \mathrm{mg}$ a.i./pot., whereas the shortest plants were those grown in clay+sand and treated with paclobutrazol at 3 or $4.5 \mathrm{mg}$ a.i./pot, or sprayed with Pix at 1000 or $2000 \mathrm{ppm}$, as well as plants grown in clay+peat

Table (3): Effect of growing media and growth regulator treatments on plant fresh weight of sunflower (Helianthus annuus) during 2007 and 2008 seasons.

\begin{tabular}{|c|c|c|c|c|c|}
\hline \multirow{3}{*}{$\begin{array}{l}\text { *Growth regulator } \\
\text { treatments }(\mathbf{G R})\end{array}$} & \multicolumn{5}{|c|}{ Plant fresh weight (g) } \\
\hline & \multicolumn{3}{|c|}{ Growing media (GM) } & \multicolumn{2}{|c|}{ Mean (GR) } \\
\hline & Clay & Clay+ sand & Clay+ peat & Sand+ peat & \\
\hline & \multicolumn{5}{|c|}{ First Season (2007) } \\
\hline Control & 25.19 & 16.30 & 43.94 & 28.70 & 28.53 \\
\hline Pac (1.5 mg a.i./pot) & 22.19 & 16.54 & 48.82 & 39.58 & 31.78 \\
\hline Pac (3 mg a.i./pot) & 26.93 & 11.11 & 40.10 & 47.49 & 31.41 \\
\hline Pac (4.5 mg a.i./pot) & 18.64 & 16.06 & 56.29 & 51.14 & $\mathbf{3 5 . 5 3}$ \\
\hline Pac (6 mg a.i./pot) & 16.21 & 15.24 & 25.76 & 18.43 & 18.91 \\
\hline Pix (500 ppm) & 28.08 & 18.97 & 46.02 & 24.65 & 29.43 \\
\hline Pix (1000 ppm) & 27.11 & 27.61 & 31.03 & 26.07 & 27.95 \\
\hline Pix (1500 ppm) & 21.28 & 16.78 & 32.47 & 18.52 & 22.26 \\
\hline Pix (2000 ppm) & 18.81 & 21.85 & 43.79 & 25.82 & 27.57 \\
\hline Mean (GM) & 22.71 & 17.83 & 40.91 & 31.15 & \\
\hline \multicolumn{6}{|l|}{ LSD (0.05) } \\
\hline GR & \multicolumn{5}{|c|}{0.85} \\
\hline GM & \multicolumn{5}{|c|}{0.56} \\
\hline \multirow[t]{2}{*}{ GR X GM } & \multicolumn{5}{|c|}{1.69} \\
\hline & \multicolumn{5}{|c|}{ Second Season (2008) } \\
\hline Control & 18.51 & 14.51 & 15.81 & 13.88 & 15.68 \\
\hline Pac (1.5 mg a.i./pot) & 22.60 & 20.96 & 18.80 & 30.22 & 23.15 \\
\hline Pac (3 mg a.i./pot) & 15.41 & 13.84 & 14.56 & 15.29 & 14.77 \\
\hline Pac (4.5 mg a.i./pot) & 18.67 & 16.12 & 22.41 & 17.72 & 18.73 \\
\hline Pac (6 mg a.i./pot) & 13.27 & 18.64 & 26.86 & 16.09 & 18.71 \\
\hline Pix (500 ppm) & 14.38 & 20.46 & 31.46 & 15.34 & 20.41 \\
\hline Pix (1000 ppm) & 17.98 & 16.90 & 33.89 & 11.08 & 19.96 \\
\hline Pix (1500 ppm) & 22.20 & 13.62 & 36.17 & 14.49 & 21.62 \\
\hline Pix (2000 ppm) & 20.42 & 25.17 & 34.31 & 10.91 & 22.70 \\
\hline Mean (GM) & 18.16 & 17.80 & 26.03 & 16.11 & \\
\hline \multicolumn{6}{|l|}{ LSD (0.05) } \\
\hline GR & \multicolumn{5}{|c|}{1.32} \\
\hline GM & \multicolumn{5}{|c|}{0.88} \\
\hline GR X GM & \multicolumn{5}{|c|}{2.64} \\
\hline
\end{tabular}

whereas the shortest plants were those grown in clay or clay+sand, and treated with paclobutrazol at 3, 4.5 or $6 \mathrm{mg}$ a.i./pot, as well as plants grown in clay+sand and sprayed with Pix at 1000 ppm (with no significant difference between the values and sprayed with Pix at 500, 1500 or 2000 ppm.

\subsubsection{Plant (leaves+stems+roots) fresh and dry weights}

The data presented in Tables (3) and (4) show 
annuus) plants grown in clay+peat had significantly heavier fresh and dry weights, compared to plants grown in any other potting medium. On the other hand, the lowest mean values in the first season were obtained from plants grown in clay+sand, while the lowest values in the second season were obtained from plants grown in sand+peat. mean values) was recorded in plants treated with the highest paclobutrazol rate $(6 \mathrm{mg}$ a.i./pot). Similar reductions in plant fresh and dry weights as a result of growth retardant treatments have been reported in a number of ornamental plant species, including sunflower [Starman (1987), Starman et al. (1989), and Hassanein et al. (2001)]. On the other hand, the highest fresh weight in the first season was that of plants

Table (4): Effect of growing media and growth regulator treatments on plant dry weight of sunflower (Helianthus annuus) during 2007 and 2008 seasons.

\begin{tabular}{|c|c|c|c|c|c|}
\hline \multirow{3}{*}{$\begin{array}{l}\text { *Growth regulator } \\
\text { treatments }(\mathbf{G R})\end{array}$} & \multicolumn{5}{|c|}{ Plant dry weight (g) } \\
\hline & \multicolumn{4}{|c|}{ Growing media (GM) } & \multirow{2}{*}{ Mean (GR) } \\
\hline & Clay & Clay+ sand & Clay+ peat & Sand+ peat & \\
\hline & \multicolumn{5}{|c|}{ First Season (2007) } \\
\hline Control & 5.85 & 3.01 & 9.98 & 6.59 & 6.36 \\
\hline Pac (1.5 mg a.i./pot) & 4.21 & 3.75 & 9.65 & 7.37 & 6.24 \\
\hline Pac (3 mg a.i./pot) & 3.35 & 2.63 & 8.68 & 7.24 & 5.47 \\
\hline Pac (4.5 mg a.i./pot) & 2.66 & 4.41 & 9.34 & 7.71 & 6.03 \\
\hline Pac (6 mg a.i./pot) & 3.12 & 3.02 & 4.92 & 4.14 & 3.80 \\
\hline Pix (500 ppm) & 5.59 & 4.41 & 12.62 & 6.25 & 7.22 \\
\hline Pix (1000 ppm) & 3.13 & 3.84 & 6.53 & 5.93 & 4.86 \\
\hline Pix (1500 ppm) & 4.65 & 3.69 & 6.57 & 3.87 & 4.70 \\
\hline Pix (2000 ppm) & 4.46 & 4.90 & 8.11 & 5.34 & 5.70 \\
\hline Mean (GM) & 4.11 & 3.74 & 8.49 & 6.05 & \\
\hline \multicolumn{6}{|l|}{ LSD (0.05) } \\
\hline GR & \multicolumn{5}{|c|}{2.46} \\
\hline GM & \multicolumn{5}{|c|}{0.73} \\
\hline \multirow[t]{2}{*}{ GR X GM } & \multicolumn{5}{|c|}{2.20} \\
\hline & \multicolumn{5}{|c|}{ Second Season (2008) } \\
\hline Control & 3.70 & 2.90 & 3.16 & 2.78 & 3.14 \\
\hline Pac (1.5 mg a.i./pot) & 4.52 & 4.29 & 4.21 & 4.89 & 4.48 \\
\hline Pac (3 mg a.i./pot) & 3.08 & 2.77 & 3.16 & 3.06 & 3.02 \\
\hline Pac (4.5 mg a.i./pot) & 3.78 & 3.47 & 4.68 & 2.94 & 3.72 \\
\hline Pac (6 mg a.i./pot) & 2.90 & 3.73 & 5.57 & 3.36 & 3.89 \\
\hline Pix (500 ppm) & 2.88 & 4.09 & 3.94 & 2.77 & 3.42 \\
\hline Pix (1000 ppm) & 2.95 & 3.18 & 6.53 & 2.22 & 3.72 \\
\hline Pix (1500 ppm) & 3.94 & 2.97 & 4.33 & 2.55 & 3.45 \\
\hline Pix (2000 ppm) & 3.78 & 5.34 & 5.86 & 2.18 & 4.29 \\
\hline Mean (GM) & 3.50 & 3.64 & 4.61 & 2.97 & \\
\hline \multicolumn{6}{|l|}{ LSD (0.05) } \\
\hline GR & \multicolumn{5}{|c|}{0.38} \\
\hline GM & \multicolumn{5}{|c|}{0.25} \\
\hline GR X GM & \multicolumn{5}{|c|}{0.76} \\
\hline
\end{tabular}

\footnotetext{
* Pac = Paclobutrazol
}

The effect of the growth retardants on plant fresh and dry weights differed from one season to the other. In the first season, the greatest reduction in plant fresh and dry weights (i.e. the lowest receiving paclobutrazol at $4.5 \mathrm{mg}$ a.i./pot, while the highest dry weight was obtained from plants sprayed with Pix at $500 \mathrm{ppm}$. In the second season, most of the growth regulator treatments 
gave higher plant fresh and dry weights, compared to the control. The only treatment which gave lower values than the control was the application of paclobutrazol at $3 \mathrm{mg}$ a.i./pot.

The results recorded in the two seasons (Tables 3 and 4) also show that using the different combinations of growing media and growth retardant treatments caused considerable differences in plant fresh and dry weights. In the first season, the heaviest fresh weight was that of plants grown in clay+peat and treated with paclobutrazol at $4.5 \mathrm{mg}$ a.i./pot, whereas in the second one, the heaviest fresh weight was obtained from plants grown in the same medium (clay+peat), but sprayed with Pix at $1500 \mathrm{ppm}$. The heaviest plant dry weight was also obtained from plants grown in clay+peat, which were sprayed with Pix at $500 \mathrm{ppm}$ (in the first season) or $200 \mathrm{ppm}$ (in the second one).

Table (5): Effect of growing media and growth regulator treatments on flower-head diameter of sunflower (Helianthus annuus) during 2007 and 2008 seasons.

\begin{tabular}{|c|c|c|c|c|c|}
\hline \multirow{3}{*}{$\begin{array}{l}* \text { Growth regulator } \\
\text { treatments }(\mathbf{G R})\end{array}$} & \multicolumn{5}{|c|}{ Flower-head diameter $(\mathrm{cm})$} \\
\hline & \multicolumn{4}{|c|}{ Growing media (GM) } & \multirow[b]{2}{*}{ Mean $(\mathbf{G R})$} \\
\hline & Clay & Clay+ sand & Clay+ peat & $\begin{array}{c}\text { Sand+ } \\
\text { peat }\end{array}$ & \\
\hline & \multicolumn{5}{|c|}{ First Season (2007) } \\
\hline Control & 10.63 & 10.03 & 11.00 & 10.44 & 10.52 \\
\hline Pac (1.5 mg a.i./pot) & 10.50 & 10.63 & 11.38 & 11.19 & 10.92 \\
\hline Pac (3 mg a.i./pot) & 9.50 & 8.25 & 11.56 & 9.88 & 9.80 \\
\hline Pac (4.5 mg a.i./pot) & 8.63 & 8.69 & 12.63 & 10.88 & 10.20 \\
\hline Pac (6 mg a.i./pot) & 7.69 & 7.81 & 10.50 & 9.31 & 8.83 \\
\hline Pix (500 ppm) & 9.38 & 8.88 & 10.56 & 10.00 & 9.70 \\
\hline Pix (1000 ppm) & 9.38 & 6.44 & 9.31 & 8.56 & 8.42 \\
\hline Pix (1500 ppm) & 7.81 & 8.38 & 10.25 & 9.31 & 8.94 \\
\hline Pix (2000 ppm) & 8.81 & 7.69 & 11.56 & 10.00 & 9.52 \\
\hline Mean (GM) & 9.15 & 8.53 & 10.97 & 9.95 & --- \\
\hline \multicolumn{6}{|l|}{ LSD (0.05) } \\
\hline GR & \multicolumn{5}{|c|}{0.45} \\
\hline GM & \multicolumn{5}{|c|}{0.29} \\
\hline GR X GM & \multicolumn{5}{|c|}{0.89} \\
\hline & \multicolumn{5}{|c|}{ Second Season (2008) } \\
\hline Control & 9.13 & 9.03 & 10.63 & 9.69 & 9.62 \\
\hline Pac (1.5 mg a.i./pot) & 8.18 & 8.41 & 10.83 & 8.10 & 8.88 \\
\hline Pac (3 mg a.i./pot) & 7.85 & 7.88 & 10.51 & 9.93 & 9.04 \\
\hline Pac (4.5 mg a.i./pot) & 8.06 & 7.85 & 9.24 & 7.83 & 8.24 \\
\hline Pac (6 mg a.i./pot) & 6.81 & 7.88 & 10.13 & 8.03 & 8.21 \\
\hline Pix (500 ppm) & 7.56 & 8.63 & 8.99 & 7.48 & 8.16 \\
\hline Pix (1000 ppm) & 8.85 & 7.34 & 8.60 & 7.95 & 8.18 \\
\hline Pix (1500 ppm) & 7.66 & 8.68 & 9.63 & 6.54 & 8.13 \\
\hline Pix (2000 ppm) & 7.96 & 7.63 & 8.13 & 6.56 & 7.57 \\
\hline Mean (GM) & 8.01 & 8.14 & 9.63 & 8.01 & --- \\
\hline \multicolumn{6}{|l|}{ LSD (0.05) } \\
\hline GR & \multicolumn{5}{|c|}{0.68} \\
\hline GM & \multicolumn{5}{|c|}{0.45} \\
\hline GR X GM & \multicolumn{5}{|c|}{1.36} \\
\hline
\end{tabular}

\footnotetext{
$*$ Pac $=$ Paclobutrazol
} 
From the above results, it is clear that the mixture of clay + peat $(1: 1, \mathrm{v} / \mathrm{v})$ was the best tested medium for growing sunflower plants, as it gave the highest values for the different vegetative growth parameters. This enhancement of vegetative growth may be attributed to the improvement in soil physical properties as a result of using these two components (clay and peat). The use of clay ensures a high water holding capacity, and a high cation exchange capacity, while peat increases soil aeration and resistance to compaction. As a result, higher absorption of water and nutrients from the soil takes place, thus enabling photosynthesis to occur efficiently within the plant leaves (Hartmann et al., 1981).
Also, the recorded results show that, for the best control of plant height, the plants should be treated with paclobutrazol at the rate of $6 \mathrm{mg}$ a.i./pot, or Pix at $2000 \mathrm{ppm}$. The reduction in plant height as a result of the growth retardant treatments can be explained by the role played by these synthetic chemicals in interfering with the synthesis of gibberellins, as mentioned by Lockhart (1962) on Phaseolus vulgaris, Dennis et al. (1965) on Echinocystis macrocarpa, Harada and Lang (1965) on Fusarium moniliforme, Goldsmith et al. (1983) on Gibberella fujikuroi and Stang and Weis (1984) on many monocot and dicot plants.

Table (6): Effect of growing media and growth regulator treatments on fresh weight of flowers in sunflower (Helianthus annuus) during 2007 and 2008 seasons.

\begin{tabular}{|c|c|c|c|c|c|}
\hline \multirow{3}{*}{$\begin{array}{l}* \text { Growth regulator } \\
\text { treatments }(\mathbf{G R})\end{array}$} & \multicolumn{5}{|c|}{ Fresh weight of flower-heads (g/plant) } \\
\hline & \multicolumn{4}{|c|}{ Growing media (GM) } & \multirow{2}{*}{ Mean (GR) } \\
\hline & Clay & Clay+ sand & Clay+ peat & Sand+ peat & \\
\hline & \multicolumn{5}{|c|}{ First Season (2007) } \\
\hline Control & 11.00 & 6.62 & 21.19 & 12.00 & 12.70 \\
\hline Pac (1.5 mg a.i./pot) & 10.74 & 10.76 & 23.47 & 17.77 & 15.68 \\
\hline Pac (3 mg a.i./pot) & $\mathbf{8 . 8 8}$ & 5.84 & 20.62 & 19.78 & 13.78 \\
\hline Pac (4.5 mg a.i./pot) & 7.82 & 8.13 & 22.59 & 19.67 & 14.55 \\
\hline Pac (6 mg a.i./pot) & 8.32 & 8.27 & 14.11 & 9.19 & 9.97 \\
\hline Pix (500 ppm) & 11.34 & 8.94 & 25.06 & 13.32 & 14.67 \\
\hline Pix (1000 ppm) & 10.00 & 9.51 & 16.79 & 14.94 & 12.81 \\
\hline Pix (1500 ppm) & 10.34 & 8.33 & 17.47 & 9.92 & 11.51 \\
\hline Pix (2000 ppm) & 10.05 & 11.41 & 17.61 & 13.15 & 13.05 \\
\hline Mean (GM) & 9.83 & 8.65 & 19.88 & 14.42 & \\
\hline \multicolumn{6}{|l|}{ LSD (0.05) } \\
\hline GR & \multicolumn{5}{|c|}{3.32} \\
\hline GM & \multicolumn{5}{|c|}{2.21} \\
\hline \multirow[t]{2}{*}{ GR X GM } & \multicolumn{5}{|c|}{6.63} \\
\hline & \multicolumn{5}{|c|}{ Second Season (2008) } \\
\hline Control & 6.37 & 3.26 & 7.60 & 4.69 & 5.48 \\
\hline Pac (1.5 mg a.i./pot) & 11.46 & 7.91 & 10.18 & 8.94 & 9.62 \\
\hline Pac (3 mg a.i./pot) & 11.18 & 6.61 & 12.46 & 6.08 & 9.08 \\
\hline Pac (4.5 mg a.i./pot) & 6.60 & 5.85 & 9.63 & 5.21 & 6.82 \\
\hline Pac (6 mg a.i./pot) & 10.73 & 8.82 & 11.82 & 5.00 & 9.09 \\
\hline Pix (500 ppm) & 8.30 & 5.25 & 13.62 & 3.36 & 7.63 \\
\hline Pix (1000 ppm) & 6.42 & 4.58 & 13.93 & 5.35 & 7.57 \\
\hline Pix (1500 ppm) & 8.71 & 6.30 & 9.13 & 4.88 & 7.25 \\
\hline Pix (2000 ppm) & 10.17 & 9.95 & 17.29 & 4.19 & 10.40 \\
\hline Mean (GM) & 8.88 & 6.50 & 11.74 & 5.30 & \\
\hline \multicolumn{6}{|l|}{ LSD (0.05) } \\
\hline GR & \multicolumn{5}{|c|}{2.50} \\
\hline GM & \multicolumn{5}{|c|}{1.67} \\
\hline GR X GM & \multicolumn{5}{|c|}{5.01} \\
\hline
\end{tabular}

$*$ Pac $=$ Paclobutrazol 


\subsection{Flowering characteristics}

\subsubsection{Flower head-diameter}

The data presented in Table (5) show that flower-head diameter of Helianthus annuus plants was significantly affected by the medium in which the plants were grown. In both seasons, flower heads produced by plants grown in clay + peat were significantly larger (i.e. had higher diameters) than those produced by plants grown in any other potting medium. It is also clear from the data in Table (5) that in both seasons, most of the growth retardant treatments caused decreases in flower-head diameter, compared to that of the control plants. Only one exception to this general trend was recorded in the first season, with the plants that were treated using paclobutrazol at 1.5 $\mathrm{mg}$ a.i./pot giving an insignificantly higher value than the control. Reductions in flower diameter as a result of using growth retardant treatments have been reported on a number of ornamental plant species, including sunflower [Lovett and Campbell (1973), Aboushoba et al. (1984), Starman et al. (1990), Anton et al. (1995), Whipker and McCall (2000), Hassanein et al. (2001)], Tagetes erecta (Girwani et al., 1990), Fuchsia magellanica ( $\mathrm{Gad}$ et al., 1997), and

Table (7): Effect of growing media and growth regulator treatments on dry weight of flowers in sunflower (Helianthus annuus) during 2007 and 2008 seasons.

\begin{tabular}{|c|c|c|c|c|c|}
\hline \multirow{3}{*}{$\begin{array}{l}\text { *Growth regulator } \\
\text { treatments }(\mathbf{G R})\end{array}$} & \multicolumn{5}{|c|}{ Dry weight of flowers (g\plant) } \\
\hline & \multicolumn{4}{|c|}{ Growing media (GM) } & \multirow[b]{2}{*}{ Mean $(\mathbf{G R})$} \\
\hline & Clay & $\begin{array}{c}\text { Clay+ } \\
\text { sand }\end{array}$ & Clay+ peat & Sand+ peat & \\
\hline & \multicolumn{5}{|c|}{ First Season (2007) } \\
\hline Control & 2.31 & 1.19 & 3.95 & 2.16 & 2.40 \\
\hline Pac (1.5 mg a.i./pot) & 1.85 & 1.74 & 4.01 & 3.08 & 2.67 \\
\hline Pac (3 mg a.i./pot) & 1.52 & 1.02 & 4.02 & 3.40 & 2.49 \\
\hline Pac (4.5 mg a.i./pot) & 1.25 & 1.54 & 4.50 & 2.61 & 2.47 \\
\hline Pac (6 mg a.i./pot) & 1.47 & 1.44 & 2.42 & 1.71 & 1.76 \\
\hline Pix (500 ppm) & 2.28 & 1.75 & 3.84 & 2.53 & 2.60 \\
\hline Pix (1000 ppm) & 1.35 & 1.59 & 3.18 & 2.22 & 2.08 \\
\hline Pix (1500 ppm) & 1.92 & 1.68 & 3.35 & 1.91 & 2.21 \\
\hline Pix (2000 ppm) & 1.82 & 2.12 & 3.73 & 2.37 & 2.51 \\
\hline Mean (GM) & 1.75 & 1.56 & 3.67 & 2.44 & \\
\hline \multicolumn{6}{|l|}{ LSD (0.05) } \\
\hline GR & \multicolumn{5}{|c|}{0.57} \\
\hline GM & \multicolumn{5}{|c|}{$\mathbf{0 . 3 8}$} \\
\hline \multirow[t]{2}{*}{ GR X GM } & \multicolumn{5}{|c|}{1.13} \\
\hline & \multicolumn{5}{|c|}{ Second Season (2008) } \\
\hline Control & 1.27 & 0.65 & 1.52 & 0.94 & 1.10 \\
\hline Pac (1.5 mg a.i./pot) & 2.29 & 1.58 & 2.04 & 1.79 & 1.93 \\
\hline Pac (3 mg a.i./pot) & 2.24 & 1.32 & 2.49 & 1.22 & 1.82 \\
\hline Pac (4.5 mg a.i./pot) & 1.32 & 1.17 & 1.93 & 1.04 & 1.36 \\
\hline Pac (6 mg a.i./pot) & 2.15 & 1.76 & 2.36 & 1.00 & 1.82 \\
\hline Pix (500 ppm) & 1.66 & 1.05 & 2.72 & 0.67 & 1.53 \\
\hline Pix (1000 ppm) & 1.28 & 0.92 & 2.79 & 1.07 & 1.51 \\
\hline Pix (1500 ppm) & 1.74 & 1.26 & 1.83 & 0.98 & 1.45 \\
\hline Pix (2000 ppm) & 2.03 & 1.99 & 3.46 & 2.37 & 2.46 \\
\hline Mean (GM) & 1.78 & 1.30 & 2.35 & 1.23 & \\
\hline \multicolumn{6}{|l|}{ LSD (0.05) } \\
\hline GR & \multicolumn{5}{|c|}{$\mathbf{0 . 5 0}$} \\
\hline GM & \multicolumn{5}{|c|}{0.33} \\
\hline GR X GM & \multicolumn{5}{|c|}{1.00} \\
\hline
\end{tabular}

* Pac $=$ Paclobutrazol 
Reichardia tingitana (Banon et al., 2003).

Regarding the interaction between the effects of growing media and growth retardant treatments on flower-head diameter, the results presented in Table (5) show that, in general, combining the use of clay+peat (as the potting medium) with the different growth retardant treatments gave higher values than those recorded with other growing media (regardless of the growth retardant treatments). The data in Table (5) also show that the largest flower-heads were those produced by plants grown in clay+peat and treated with paclobutrazol at $4.5 \mathrm{mg}$ a.i./pot (in the first season) or at $1.5 \mathrm{mg}$ a.i./pot (in the second season).

\subsubsection{Fresh and dry weights of flower-head}

The results recorded in the two seasons on the fresh and dry weights of Helianthus annuus flower-heads (Tables 6 and 7) show that the potting media had a considerable effect on these two flowering characteristics. In both seasons, flower-heads produced by plants grown in clay+peat were significantly heavier (i.e. had higher fresh and dry weights) than those produced by plants grown in any of the other tested potting media.

Regarding the effect of growth retardant treatments on the fresh and dry weights of the flower head, the data in Tables (6) and (7) show that, in general, most of the tested treatments increased the recorded values, compared to the control, especially in the second season. In the first season, the highest fresh and dry weights of flower-heads were obtained from plants that had been treated with the lowest paclobutrazol rate (1.5 mg a.i./pot), whereas in the second season the highest values were obtained from plants sprayed with the highest Pix concentration (2000 ppm). Similar increases in the fresh and dry weights of flowers as a result of paclobutrazol or mepiquat chloride treatments have been reported by Maghazy (1991) on Viola odorata, Haggag (1997) on chrysanthemum, Singh (2003) on Calendula officinalis, and Singh (2004) on African marigold.

The data in Tables (6) and (7) also show that considerable differences were recorded in the fresh and dry weights of flower-heads as a result of using the various combinations of potting media and growth retardant treatments. In the first season, the heaviest fresh flower-heads were produced by plants grown in clay+peat and sprayed with Pix at $500 \mathrm{ppm}$, while the highest dry weight was obtained from plants grown in the same medium (clay+peat) but treated with paclobutrazol at $4.5 \mathrm{mg}$ a.i./pot. In the second season, the highest fresh and dry weights of flower heads were obtained from plants grown in clay+peat and sprayed with the highest Pix concentration (2000 ppm).

\subsection{Recommendation}

From the above results, it can be recommended that for the production of sunflower (Helianthus annuus) as a flowering pot plant, it should be grown in a mixture of clay+peat (1:1, $\mathrm{v} / \mathrm{v})$, as this growing medium gave the highest values for the different vegetative growth and flowering characteristics. For the best height control (i.e. the shortest plants), sunflower should be treated with paclobutrazol as a soil drench at 6 $\mathrm{mg}$ a.i./pot, or Pix (mepiquat chloride) as a foliar spray at $2000 \mathrm{ppm}$.

\section{REFERENCES}

Aboushoba L.M., Shahin N. and El-Afry M. M. (1984). Physiological response of sunflower plants to foliar application of CCC and boron. Tropenlandwirt; 85/86(October-April): 32-40.

Anton N.A., Basseim M.M., Attia S .A. M. and Kadry W. (1995). Response of sunflower plants to some growth regulators and different levels of nitrogen fertilizer under sandy soil conditions. Annals of Agric., Sci., Moshtohor., 33(3): 921-932.

Banon S., Ochoa J., Fernandez J.A., Sanchez J.J.M., Franco J.A and Gonzalez A. (2003). Plant growth retardants for introduction of native Reichardia tingitana. Acta Hortic., (598): 271-277.

Bhat N.R. and Tayama H .K. (1989). Performance of growing media drench applied A-Rest in various container media part 1 . Ohio Florists Association Bulletin, (713): 6-7.

Bonacin G.A, Rodrigues T.de.J.D and Mattiuz C.F.M. (2006). Application of growth retardants in hybrids of ornamental sunflower. Revista Brasileira de Hortic., Ornamental, 12(1): 37-42.

Cox D.A. and Keever G.J. (1988). Paclobutrazol inhibits growth of zinnia and geranium. Hort Sci., 23(6,I): 1029-1030.

Dasoju S, Evans M.R. and Whipker B.E. (1998). Paclobutrazol drenches control growth of potted sunflowers. Hort Technology, 8(2): 235-237.

Dennis D.T., Upper C. D. and West C .A .(1965). An enzymic site of inhibition of gibberellins biosynthesis by Amo 1618 and other plant growth retardants. Plant Physiology, 40(5) :948-952.

Gad M., Schmidt G. and Gerzson L. (1997). Comparison of application methods of growth retardants on the growth and flowering of 
Fuchsia magellanica Lam. Horticultural Science, 29: 1/2, 70-73. 11.

Gimelli F., Leporati A. and Maggiora L. (2003). The all year round cultivation of cut sunflower in San Remo District. Acta Hortic., 614(Vol 2): 553-560.

Girwani A., Babu R.S. and Chandrasekhar R. (1990). Response of marigold (Tagetes erecta) to growth-regulators and Zinc. Indian J. of Agric. Sci., 60(3): 220-222.

Goldsmith I.R., Hood K.A. and Macmillan J. (1983). Inhibition of gibberellins biosynthesis in Gibberella fujikuroi by PP333.Sci. symposium on Ergosterol biosynthesis inhibitors, Reading, U. K. 20-24 Mar. 1983.

Haggag A.A. (1997). Physiological Studies on Chrysanthemum Plant. Ph. D. Thesis, Fac. of Agric., Cairo Univ.

Harada H. and Lang A. (1965). Effect of some (2chloroethy1) trimethylammonium chloride analogs and other growth retardants on gibberellins biosynthesis in Fusarium moniliforme. Plant Physiology, 40(1):176-183.

Hartmann T. H., Flocker W. J. and Kofranek A. M. (1981). Growth, development and utilization of cultivated plants. Englewood Cliffs, New Jersey 07632, pp. 140.

Hassanein M.S., Rashad E.M. and Magda A.F.S. (2001). Physiological response of two sunflower (Helianthus annuus L.) cultivars to some growth retardants in newly cultivated sandy lands. Annals of Agric. Sci., Moshtohor, 39(4): 1887-1905.

Incrocci G., Mugnai S, Vernieri P., Serra G. and Tognoni F. (2003). Production of sunflowers as flowering pot plants. Colture Protette.; 32(2): 105-114.

Law D.M. and Hamilton R.H. (1989). Reduction in the free indole-3- acetic acid levels in Alaska pea by the gibberellins boisynthesis inhibitor uniconazole .Physiol. plant .76:535538.

Lockhart J.A. (1962). Kinetic studied of certain anti-gibberellins. Plant Physiology 37(6):759764.

Lovett J.V. and Campbell D.A. (1973). Effects of CCC and moisture stress on sunflower. Experimental Agric., 9(4): 329-336.

Maghazy E.I. (1991). Physiological Studies on Viola odorata L. Ph. D. Thesis, Fac. Agric., Suez Canal Univ.

Pinto A.C.R., Rodrigues T. de. J.D., Leite I.C. and Barbosa J.C. (2005). Growth retardants on development and ornamental quality of potted 'Lilliput' Zinnia elegans Jacq. Scientia Agricola, 62(4): 337-345.
Singh A. K. (2003). Effect of SADH and PP333 on growth and flowering attributes in Calendula officinalis. Journal of Medicinal and Aromatic Plant Science, 25(2): 424-426.

Singh A. K. (2004). Studies on effect of growth retardants on growth and flowering in african marigold. Horticultural Journal., 17(1): 7982.

Stang E.J. and Weis G.G. (1984). Influence of paclobutrazol plant growth regulator on strawberry plant growth, fruiting and runner suppression. Hort. Science 19 (5): 643-645.

Starman T.W. (1987). Effects of the growth retardant ancymidol on sunflower morphology, pigments, and leaf anatomy. Dissertation Abst., International B. Sci. and Engineering, 47 (7): 2707B.

Starman T.W., Kelly J.W. and Pemberton H.B. (1989). Characterization of ancymidol effects on growth and pigments of Helianthus annuus cultivars. Journal of the American Society for Hortic. Sci., 114(3): 427-430.

Starman T. W., Kelly J.W. and Pemberton H.B. (1990). The influence of ancymidol on morphology, anatomy, and chlorophyll levels in developing and mature Helianthus annuus leaves. Plant-Growth-Regulation., 9(3): 193200.

Steel R. G. and Torrie S. H. (1980). Principles and Procedures of Statistics. Second Ed., McGraw-Hill Inc., New York. pp. 63.

Taychasinpitak T. and Manochai B. (2003). Use of growth retardant on classic zinnia (Zinnia angustifolia, Kunth) to make commercial pot plant. Kasetsart J., Natural Sci., 37(3): 243246.

Vernieri P., Incrocci G., Tognoni F. and Serra G. (2003). Effect of cultivar, timing, growth retardants, potting type on potted sunflowers production. Acta Horticulturae, 614(Vol 1): 313-318.

Wanderley C. da S., Rezende R. and Andrade C.A.B. (2007). Effect of paclobutrazol as regulator of growth in production of flowers of sunflower in hydroponic culture. Ciencia e Agrotecnologia, 31(6): 1672-1678.

Whipker B. E. and McCall I. (2000). Response of potted sunflower cultivars to daminozide foliar sprays and paclobutrazol drenches. HortTechnology, 10(1): 209-211.

Whipker B.E., McCall I., Gibson J.L and Cavins T.J. (2004). Flurprimidol foliar sprays and substrate drenches control growth of 'Pacino' pot sunflowers. HortTechnology, 14(3): 411414. 


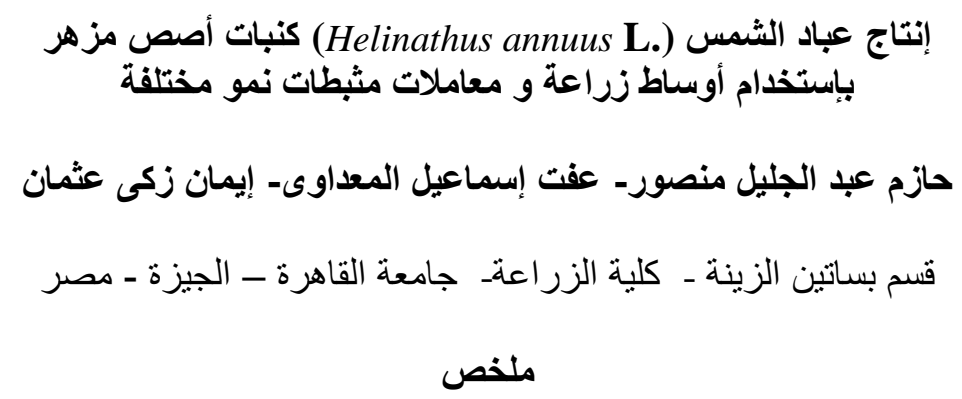

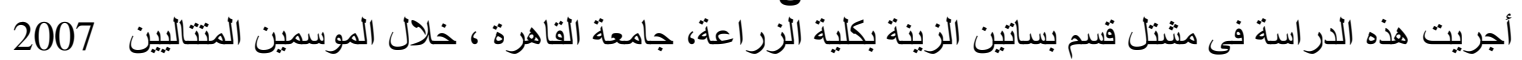

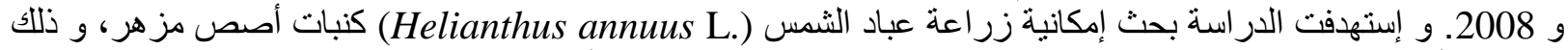

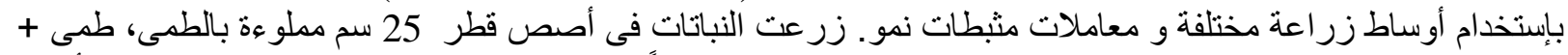

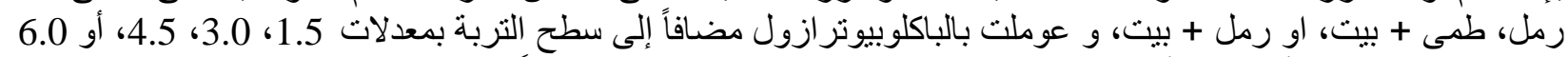

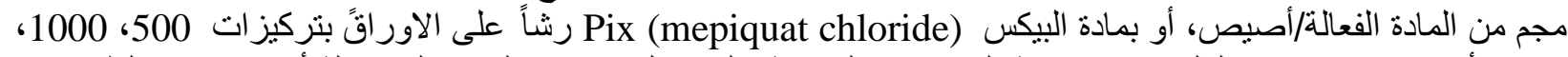

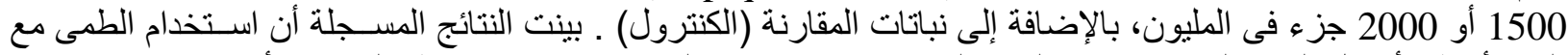

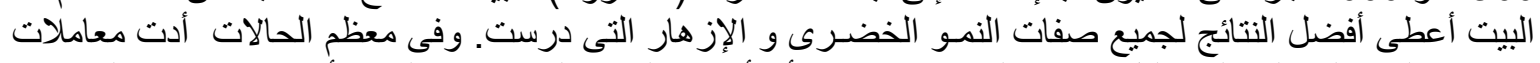

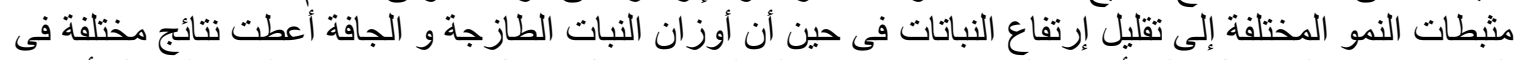

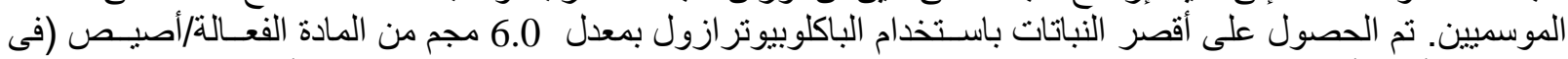

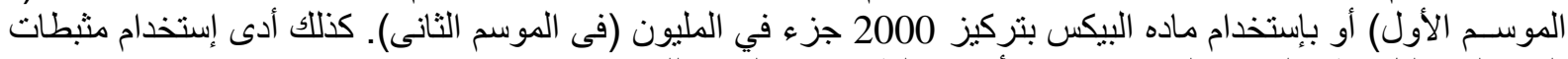

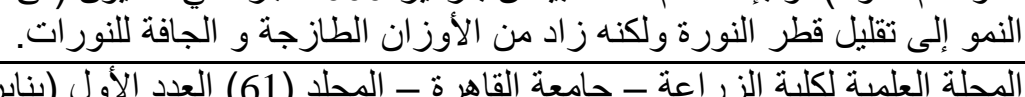

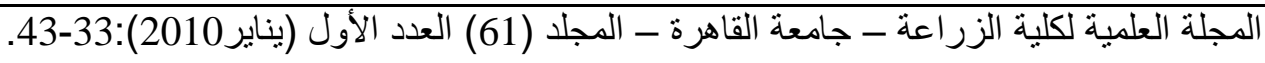

